iff

$$
\text { ? }
$$

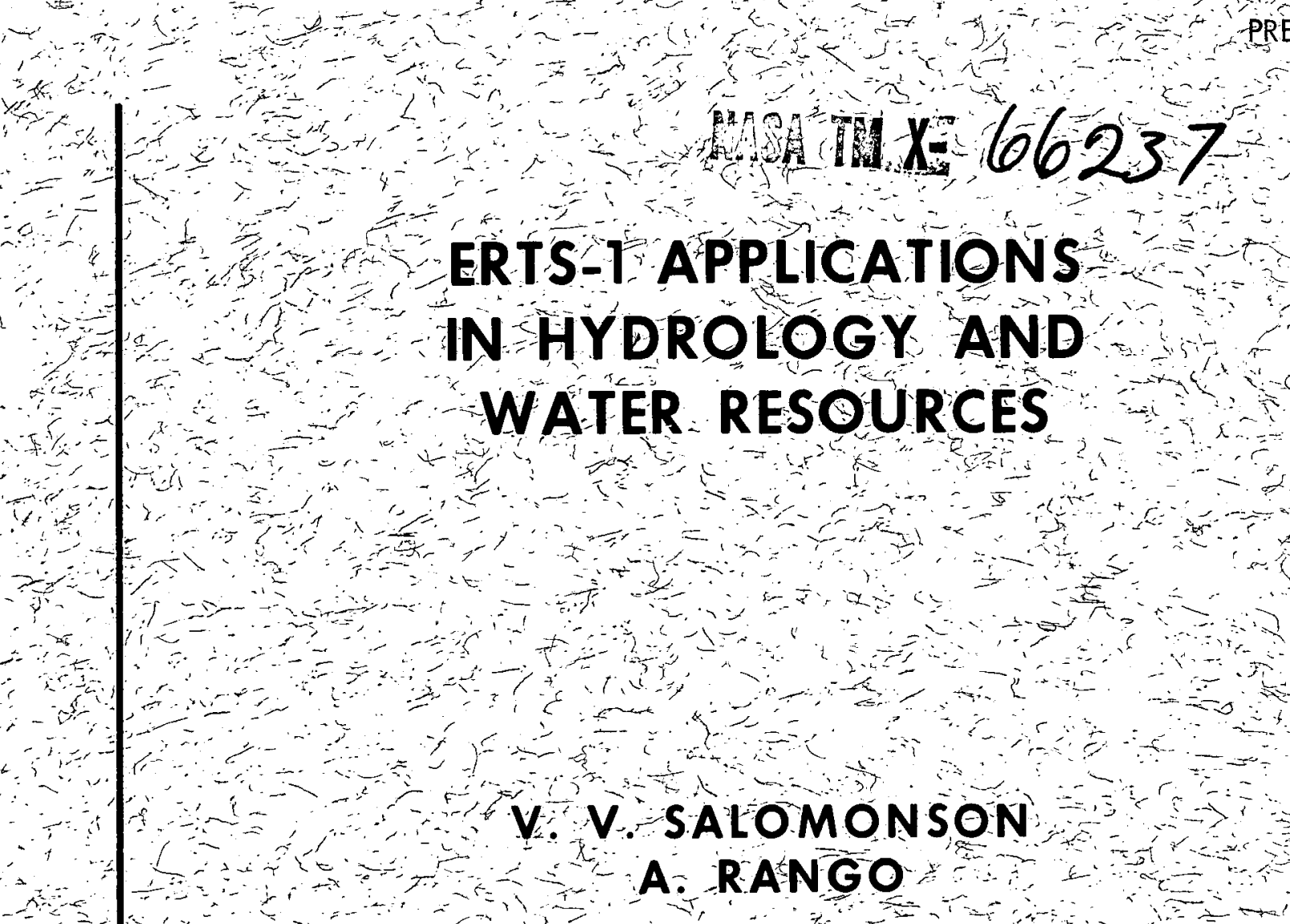

(NASA-TM-X-66237) ERTS-1 APPIICATIONS IN HYDROLOGY AND FATER RESOURCES (NASA) 25 p HC $\$ 3.25$

CSCL $08 \mathrm{H}$

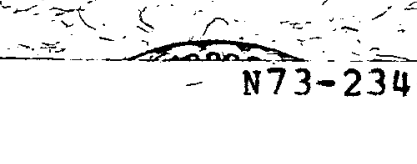

N73-234
Unclas

G3/13 02980

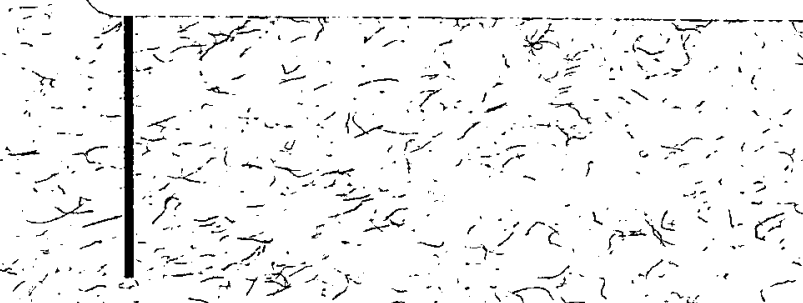

MAY 1973

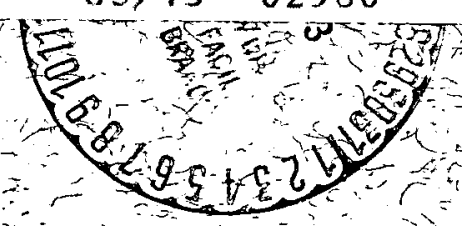

GSFC GODDARD SPACE FLIGHT CENTER GREENBELT, MARYLAND

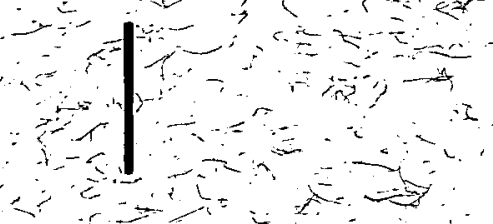




\title{
ERTS-1 APPLICATIONS IN HYDROLOGY AND \\ WATER RESOURCES
}

\author{
by \\ V. V. Salomonson
}

A. Rango

Laboratory for Meteorology and Earth Sciences

NASA/Goddard Space Flight Center

Greenbelt, Maryland 20771

Phone: 301-982-6147

Prepared for Presentation at the

93rd Annual Conference

$$
\text { of the }
$$

American Water Works Association

May $13-18,1973$

$$
\text { I }
$$




\begin{abstract}
After having been in orbit for less than one year, the Earth Resources Technology Satellite (ERTS-1) has shown that it provides very applicable data for more effective monitoring and management of surface water features over the globe. Mapping flooded areas, snowcover, and wetlands and surveying the size, type, and response of glaciers to climate are among the specific areas where ERTS-1 data have been applied. In addition the Data Collection System (DCS) has proven to be a reliable tool for gathering hydrologic data from remote regions. Turbidity variations in lakes and rivers have also been observed and related to shoreline erosion, industrial plant effluent, and overall water quality.
\end{abstract}


Illustrations

Figure 1. A portion of an ERTS-1 scene taken over Southwestern Colorado showing the Mancos River drainage basin (upper left) and portions of the La Plata, Animas, and San Juan drainage basins.

Figure 2. ERTS-1 snowcover observations in the $0.6-0.7 \mu \mathrm{m}$ spectral region. Each frame is approximately $186 \mathrm{~km}$ on a side.

Figure 3. ERTS-1 observations in two spectral bands over the Bering Glacier on 22 September 1972 in South Central Alaska. The sediment plumes are occurring in the Gulf of Alaska. The frame covers an area $186 \mathrm{~km}$ on a side.

Figure 4. Portions of two $0.8-1.1 \mu \mathrm{m}$ observations from ERTS-1 over large irrigation fields in the Tulare Lake Bed area between Fresno and Bakersfield, California.

Figure 5. A $0.8-1.1 \mu \mathrm{m}$ observation on 12 September 1972 over the Salt Lake City and Provo, Utah areas. The bright circulation feature on Utah Lake is the result of increased solar reflectance by an algal mat existing in the lake at the time of the satellite overpass.

Figure 6. Two views in the $0.8-1.1 \mu \mathrm{m}$ spectral region from ERTS-1 showing imagery taken before and during the 1973 flooding in the areas near, the confluence of the Illinois River (C), and Missouri River (B) with the Mississippi River near St. Louis (A). The flooded areas appear in the darkest tones such as those areas marked (D). At the time of the March 31 image the river stage at St. Louis was 38 feet and still rising. 


\section{ERTS-1 APPLICATIONS IN HYDROLOGY AND WATER RESOURCES}

\section{Introduction}

As man's population increases and his technology advances he requires more and more water for support of his industrial, recreational, and agricultural activities. For comparison, it has been noted ${ }^{1}$ that water demand per person in the larger cities of the United States is over twenty times that required by a person in the developing countries of the world. At the same time, present day management practices permit man to economically extract his water supply from less than $0.01 \%$ of the total water amount in the earth-atmosphere system. ${ }^{2}$ Therefore, it is apparent that water must be managed with increasing efficiency and the quantity and quality of water conserved wherever possible.

In order to become more efficient in the utilization of available water supplies and to find new sources of water, a system of observation and monitoring is required that can cover large areas on a repetitive basis and identify water resources or parameters that are related to or effect the water yield from a given region. On July 23, 1972, the National Aeronautics and Space Administration (NASA) launched from its Western Test Range in Southern California the first Earth Resources Technology Satellite (ERTS-1) into a near polar, circular orbit at an altitude near $900 \mathrm{~km}$ (500 naut. $\mathrm{mi}$ ). The orbital characteristics of this satellite and the capability of the on-board sensors ${ }^{3}$ combine to provide a system which is capable of taking remotely-sensed observations over any given point on earth once every 18 days. 
The observations taken by the sensors on ERTS-1 occur in the visible and near infrared portions of the electromagnetic spectrum. Since its launch the vast majority of observations have been acquired using the Multi-Spectral Scanner (MSS). The MSS takes observations in the $0.5-0.6,0.6-0.7,0.7-0.8$, and $0.8-1.1 \mu \mathrm{m}$ portions of the electromagnetic spectrum. The ability of the MSS to resolve objects on the earth's surface varies somewhat depending upon the geometric characteristics of a given object and its contrast with surrounding features, but generally a spatial resolution capability near $80 \mathrm{~m}$ is available. The spaceborne capabilities just described have provided an observational system that does permit one to repetitively identify water resources and hydrological features and, thereby, better enable man to meet the challenge of supporting his increased numbers and activities while at the same time preserving or improving the quality of his environment. The remainder of this paper will be devoted to describing in some detail the content and character of the ERTS-1 observations as they relate to hydrology and water resources along with providing a summary of the applications that have been made of these data during the first nine months of satellite operation.

Watershed Physiography and Land Use

A drainage basin or watershed is an open system that tends to achieve a steady state of operation over long periods. Conditions such as surface relief, slope, and channel configuration are continually attempting to adjust so as to 
achieve a balanced state wherein the quantity of debris and excess water characteristically produced by the accompanying climate are transmitted through the watershed system. Therefore, observations of basin shape, stream network character, drainage density, land use, and the changes in these parameters permit one to infer the general characteristics of the water yield from a drainage basin such as the location of groundwater and the magnitude and character of the mean runoff. Figure 1 shows a view of the Mancos River Basin and a portion of the San Juan River Basin taken on November 19, 1972 from ERTS-1. Here the basin shape, stream network, and drainage density on the Mancos River are quite visible along with the areal extent of snow cover on the drainage basin and surrounding mountains. With reference to snow cover and land use, one can note a bright, wedge-shaped, snow-covered area in the upper portions of the Mancos River watershed that stands out because of the lack of vegetation. This is an area in which a forest fire occurred during the summer of 1972 . Changes or features of this kind are not so easily or rapidly incorporated or illustrated on conventional maps. This example is intended to illustrate that the satellite imagery can delineate areas of changing land use that are significant in terms of the relative changes to be expected in the runoff from a given region.

Stoertz and Carter ${ }^{4}$ have used ERTS imagery obtained during August, September, and October of 1972 to better delineate and monitor hydrological features in a relatively large 415,000 square kilometer region in West Central South America. In the course of this investigation, ERTS-1 data were used to 
better delineate 184 drainage basins, find 20 new salars (evapotranspiration troughs), find 36 new lakes not depicted on available maps, and determine the 13 basins having the most abundant surface water resources in this region. Other physiographic and land use features are being studied successfully from ERTS-1 for water resources development and planning purposes in the lower Mekong Basin, 5 Republic of Mali, ${ }^{6}$ Lake Ontario and its basin, 7 the Potomac River Basin, 8 and many other basins in the United States and in Foreign countries. In general, it can be said that the ERTS-1 imagery can be reliably used to detect and monitor major land use changes on a repetitive basis for map scales as large as $1: 250,000$ with some features and changes detectable at larger scales.

\section{Snow Cover}

A large portion of the runoff in the Western United States results from snowmelt. Accurate prediction and management of water coming from snowmelt is very important and small increases in the accuracy of runoff prediction can mean monetary benefits amounting to millions of dollars. The ERTS-1 MSS delineates the areal extent of snow cover in the $0.5-0.6$ and $0.6-0.7 \mu \mathrm{m}$ observations quite well as indicated in Figure 1 and Figure 2. Figure 2 shows the snow cover change occurring between summer and early Fall over the remote Wind River Mountains of Western Wyoming. Results generated from ERTS-1 imagery over Alaska and Washington State show that snowlines altitudes can be estimated to the nearest 60 meters under favorable conditions and the areal 
extent of snow cover can be obtained to within $4 \%$ of drainage basin area. 9 Early results from one season show that the areal extent of snowcover can be empirically related to runoff with ascuracies that appear useful for runoff forecasting. Analysis of ERTS-1 imagery over the Salt and Verde River Watersheds of Arizona show that more detail can be derived from imagery than is normally obtained from routine aircraft surveys. 10 There is an unusual amount of runoff and flooding occurring on the Salt and Verde Rivers during the Spring of 1973 and ERTS-1 data is being evaluated and applied during this situation. For ungauged and/or inaccessible and remote watersheds, or as ancillary data for conventional in situ snowpack monitoring networks, the early results indicate that ERTS-1 data can be used profitably for better management of snowpack water resources.

Glaciology

Nearly $80 \%$ of the fresh water on the earth is contained within glaciers and icecaps. ${ }^{2}$ As a result it is important that the location, movement, and extent of this water supply be understood and monitored. The ERTS-1 observations have been particularly exciting in this regard in that they permit the inventoring of glaciers in the remote and harsh regions where they are normally located. In addition, the observation of medial morain character and surface features such as snowlines can be easily accomplished. This is illustrated in Figure 3 by ERTS-1 0.5-0.6 and 0.8-1.1 $\mu \mathrm{m}$ observations over the Bering Glacier in Central 
Alaska. This is the largest glacier on the North American continent covering approximately $200 \mathrm{~km}$ in length and $5800 \mathrm{~km}^{2}$ in surface area. One may note the wiggly or folded moraines of this glacier. This characteristic distinguishes this glacier as a surging glacier from its non-surging counterparts which have uniform moraines. Meier ${ }^{11}$ has reported viewing the recent 1800 meter surge of the Yentna Glacier near Mt. McKinley in Alaska using ERTS-1 imagery. The ERTS-1 imagery has proved to be very enlightening in understanding the 1965-1966 surge of the Bering Glacier. Inasmuch as surging glaciers occasionally block and suddenly release large amounts of melt water resulting in flood situations, it is fortunate that ERTS-1 is so applicable in monitoring this type of glacier.

One can observe sediment plumes such as those that can be seen in the $0.5-$ $0.6 \mu \mathrm{m}$ observations extending some tens of miles out into the Gulf of Alaska. These particular plumes result in large portion from glacial melt. The areas contributing to this glacial melt are delineated by the dark areas on the Bering Glacier. The dark area results from the lower reflectivity of surface water that is standing on or flowing over the surface of the glacier. Again, in remote regions this kind of information may be very valuable in locating and utilizing new sources of water.

\section{Surface Water}

In the $0.8-1.1 \mu \mathrm{m}$ region surface water contrasts markedly with surrounding dry soil and vegetated areas. As a result surface water bodies as small as one 
hectare $\left(10,000 \mathrm{~m}^{2}\right)$ can be delineated. In addition, areas of relatively high soil moisture as in the case of irrigated fields can be seen readily. Figure 4 shows portions of two ERTS $0.8-1.1 \mu \mathrm{m}$ scenes over the Tulare Lake Bed irrigated area between Bakersfield and Fresno, California. Those fields under irrigation or recently irrigated are easily distinguished. In particular, note the large field in the lower center of the right image. This field is under irrigation at the time of the satellite overpass and the wetted area in the northeast half of the field sharply contrasts with the drier southwestern half of the field. The utility of this kind of imagery for assessing the acreage under irrigation during a given period seems obvious.

ERTS-1 imagery has proven to be very applicable in inventoring and monitoring the thousands of small playa lakes in the Southern High Plains of Texas. 12,13 Gathering this kind of information in this region is completely impractical by conventional means. Nevertheless it has considerable relevance for ascertaining the portion of that region contributing heavily to evaporation, acting as sources of irrigation water or sinks for irrigation tailwater, or contributing to groundwater recharge.

Wetlands constitute a very important resource for environmental and recreational purposes. The fluctuation in wetlands area in many instances is associated with the varying ability of an area to support wildlife and recreational activities such as hunting. In addition the extent of coastal wetlands often separates lands coming under the public domain from those available for private 
enterprises. The ERTS-1 imagery can delineate the extent of wetlands, both coastal and inland, very well in the $0.8-1.1 \mu \mathrm{m}$ observations. Figure 5 shows a portion of an ERTS-1 scene south of the Great Salt Lake in Utah. The extent of the wetlands associated with the Farmington Bird Refuge can be seen to the southeast of the Great Salt Lake. Results wherein wetlands have been mapped in Alaska, ${ }^{14}$ North Dakota, 15 the Texas Gulf Coast, ${ }^{16}$ New Jersey, 17 Maryland and Georgia18 have been reported. Objective means of mapping wetlands using digital data on computer compatible tapes have achieved accuracies between 89 and $99 \% .16$

The quality of water and the stage of eutrophication in lakes can in some instances be inferred rather clearly from ERTS-1 data. The lower right hand corner of Figure 5 shows an interesting phenomenon in Utah Lake near Provo, Utah. The presence of an algal bloom is causing a strong reflection of incoming solar energy in the near infrared. Utah Lake is known for its high turbidity and algal content, but the extent of the algal bloom has never before been so dramatically observed as in this image. Note the circulation pattern outlined by the algal feature.

The extent of pollution plumes that cause color changes can be monitored in many other instances. A classic example involving a paper mill effluent plume originating on the New York side of Lake Champlain near Fort Ticonderoga has been reported. 19 The plume extends into Vermont waters and has resulted in a court action by the State of Vermont against the State of New York. Part of 
the material collected by the State of Vermont in a suit against the State of New York includes an ERTS-1 image of Lake Champlain taken on October 10, 1972 showing the extent of this effluent plume.

Sediment suspended in rivers, lakes and reservoirs create very interesting eddies and patterns in these water bodies that relate to circulation patterns such as those shown in Figures 3 and 5. These circulation patterns not only give a near-surface indication of the dynamics occurring in a water body but offer guidelines as to where conventional in-situ observations might best be placed in order to achieve maximum utilization and effectiveness. In addition, the eddies and currents represented in imagery give clues as to where shoreline erosion is occurring in lakes and how sediments or pollutants become spatially distributed as they are dumped into relatively large bodies of water.

Caution must be exercised where observing shallow water bodies in that the visible wavelengths sometimes reveal bottom features. In studies relating depth to reflectance near the Little Bahama Bank, an area with comparatively low turbidity, depth measurements to $10 \mathrm{~m}$ appear possible using the $0.5-0.6 \mu \mathrm{m}$ and $0.6-0.7 \mu \mathrm{m}$ measurements. 20 In more turbid waters bottom features deeper than $1 \mathrm{~m}$ may be obscured. In Kansas studies are being pursued wherein sunlight penetration depth and sediment load is being correlated with ERTS-1 observations. 21 In these latter studies the best correlations occur when using the 0.6-0.7 and $0.7-0.8 \mu \mathrm{m}$ observations and when sediment loads do not exceed $100 \mathrm{ppm}$. The indication seems to be that a reliable, low cost procedure for estimating suspended load in a given lake, reservoir, or stream is very possible. 
Flooding

1972 and the first part of 1973 were periods when several very damaging and significant floods occurred. Perhaps the most widely known flooding occurred along the Mississippi River and its tributaries. As mentioned in the section on surface water, the extent of standing water and areas of high soil moisture are easily observable in the $0.8-1.1 \mu \mathrm{m}$ region; therefore, these observations are quite amenable to obtaining measurements of flood inundated area, both during and several days after a flood has occurred. Figure 6 illustrates this point by showing before and after views of that portion of the Mississippi River near St. Louis, Missouri. In view of the fact that ERTS-1 imagery in a $9 \times 9$ in. standard format is very near 1:1 million scale, only a few minutes with a planimeter were required to ascertain that approximately 280,000 acres were covered by water in the scene on the right of Figure 6. Earlier and more detailed studies on the East and West Nishnabotna Rivers (September 1972 flood) in Iowa $^{22}$ and the Gila River (October 1972 flood) in Arizona ${ }^{23}$ revealed that regional flood mapping with ERTS-1 data could be accomplished on the 1:250,000 map scale with accuracies comparable to conventional aircraft surveys. In addition, the wide area coverage afforded by ERTS permitted the easy extension of the surveys to other rivers or regions not normally covered by aircraft surveys. Other studies conducted by the authors of this paper on the James River, Appomattox, and Nottoway Rivers in Virginia reveal that flooded areas associated with flood recurrence intervals as small as 1 in 20 years can be studied using 
the ERTS-1 imagery. Studies evaluating whether ERTS-1 imagery is applicable to flood plain mapping, erosional changes, and channel changes following flooding were underway at the time this article was written.

Satellite Data Relay

Although the satellite imagery provides observations of definite utility, there are some very important hydrologic parameters that are very difficult to observe via remote sensing techniques. Such parameters include stream gauge and groundwater well information, specific water quality parameters and snow depth and moisture measurements. Another very attractive and viable approach to data collection is to relay the data from remote regions via satellite to data processing and analysis centers where it can be disseminated to water management organizations. To date the Data Collection System (DCS) on ERTS-1 has proven to be a reliable system permitting the collection and relay of data to responsible agencies in time periods as small as one-half hour. A very noteworthy case in point occurred on the Verde River Watershed in Arizona during February, 1973. 24 A meteorological situation occurred where rapid snowmelt was possible and considerable amounts of water would have to be spilled from the Bartlett Reservoir causing many road closures and considerable inconvenience in the Phoenix area. At the critical time, the standard microwave telemetry system failed creating an emergency situation in which the experimental DCS system had to be employed. The critical snowmelt information was collected 
via satellite and relayed to the decision making agency (Salt River Valley Water Users Association) in $1 / 2$ hour. This information revealed that snowmelt was not occurring as rapidly as expected, larger amounts of water did not have to be released from Bartlett Reservoir, and, as a result, the number of expected road closures in the Phoenix area was reduced considerably.

The DCS is providing water quality, meteorological, stream gauge, and groundwater well information in several areas including the Delaware River Basin, 24 the Merrimack River Basin in Connecticut, and areas in Southern and Central Florida. 25 In each case the data are being relayed to responsible agencies in near real-time. In the Florida case the DCS data are being combined with imagery from the MSS to yield volumetric estimates. The collection of the data being relayed now via satellite would take weeks if it were collected by means other than data relay.

Summary

ERTS-1 has been in orbit for a little over 9 months. In the fields of water resources and hydrology it has already provided data which are applicable in the monitoring and mapping of physiography and land use in drainage basins, surface water bodies including wetlands, snowcover, flood inundated areas, and glaciers. In situ information is also being collected and relayed via satellite to water resources management agencies. The demonstration of these applications has only been possible because of the initiative displayed by the many investigators 
involved in the ERTS-1 data analysis program who recognized the potential of these data for monitoring water resources. Other results will undoubtedly come to light as these investigators have time to fully exploit the vast amounts of information already available and as the satellite continues to operate and provide new data. In addition, it is expected that many more unanticipated and specific applications will be forthcoming as more individuals and organizations become acquainted with the nature of these data and the facilities and means available for acquiring and processing it. 


\section{References}

1. Overman, Michael. Water. Doubleday \& Co. Inc., Garden City, New York (1969).

2. Todd, David K. The Water Encyclopedia. Water Information Center, Port Washington, N.Y. (1970).

3. General Electric Co. Earth Resources Technology Satellite Reference Manual. Space Division, General Electric Company, P.O. Box 8555, Philadelphia, Pa., 19101 (1972).

4. Stoertz, George E. \& Carter William D. Hydrogeology of Closed Basins and Deserts of South America, ERTS-1 Interpretations. Proc. Symp. on Signif. Results Obtained from ERTS-1, Vol. 1, New Carrollton, Md. (1973).*

5. Van Liere, William J. Applications of Multispectral Imagery to Water Resources Development Planning in the Lower Mekong Basin (Khmer Republic, Laos, Thailand, and Viet-Nam). Proc. Symp. on Signif. Results Obtained from ERTS-1, Vol. 1, New Carrollton, Md. (1973).

6. MacLeod, N. H. Applications of Remote Sensing (ERTS) to Resource Management and Development in Sahelien Africa (Republic of Mali). Proc. Symp. on Signif. Results Obtained from ERTS-1, Vol. 1, New Carrollton, Md. (1973).

\footnotetext{
*Copies of this Proceedings will be available after August 1973 from Superintendent of Documents, Government Printing Office, Washington, D. C. (20402).
} 
7. Wagner, Thomas W. \& Polcyn, Fabian C. Progress of an ERTS-Program for Lake Ontario and Its Basin. Proc. Symp. on Signif. Results Obtained from ERTS-1, Vol. 1, New Carrollton, Md. (1973).

8. Schubert, J. S. \& MacLeod, N. H. Digital Analysis of Potomac River Basin Imagery: Sedimentation Levels at the Potomac-Anacostia Confluence and Strip Mining in Allegheny County, Maryland. Proc. Symp. on Signif. Results Obtained from ERTS-1, Vol. 1, New Carrollton, Md. (1973).

9. Meier, M. F. Evaluation of ERTS Imagery for Mapping and Detection of Changes of Snowcover on Land and on Glaciers. Proc. Symp. on Signif. Results Obtained from ERTS-1, Vol. 1, New Carrollton, Md. (1973).

10. Barnes, J. C. \& Bowley, Clinton J. Use of ERTS Data for Mapping Snow Cover in the Western United States. Proc. Symp. on Signif. Results Obtained from ERTS-1, Vol. 1, New Carrollton, Md. (1973).

11. Meier, M. F. Galloping Glaciers Monitored from Space. EOS, Transactions, American Geophysical Union, 54:3: 150-151C (March 1973).

12. Baumgardner, Marion F.; Kristof, Steven J.; \& Henderson, James A. Identification and Mapping of Soils, Vegetation, and Water Resources of Lynn County, Texas by Computer Analysis of ERTS MSS Data. Proc. Symp. on Signif. Results Obtained from ERTS-1, Vol. 1, New Carrollton, Md. (1973). 
13. Reeves, C. C. Dynamics of Playa Lakes in the Texas High Plains. Proc. Symp. on Signif. Results Obtained from ERTS-1, Vol. 1, New Carrollton, Md. (1973).

14. Van Tries, Bill J. An Evaluation of Space Acquired Data as a Tool for Management of Wildlife Habitat in the State of Alaska. Proc. Symp. on Signif. Results Obtained from ERTS-1, Vol. 1, New Carrollton, Md. (1973).

15. Gilmer, David S. \& Klett, Albert T. Preliminary Evaluation of ERTS-1 for Determining Numbers and Distribution of Prairee Ponds and Lakes. Proc. Symp. on Signif. Results Obtained from ERTS-1, Vol. 1, New Carrollton, Md. (1973).

16. Flores, L. M.; Reeves, C. A.; Hixton, S. B.; \& Paris, J. F. Unsupervised Classification and Areal Measurement of Land and Water Coastal Features on the Texas Coast. Proc. Symp. on Signif. Results Obtained from ERTS-1, Vol. 1, New Carrollton, Md. (1973).

17. Mairs, Robert L.; Wobber, Frank J.; \& Garofalo, Donald. Application of ERTS-1 Data to the Protection and Management of New Jersey's Coastal Environment. Proc. Symp. on Signif. Results Obtained from ERTS-1, Vol. 1, New Carrollton, Md. (1973). 
18. Anderson, Richard R.; Carter, Virginia; \& McGinnis, John. Mapping Atlantic Coastal Marshlands, Maryland, Georgia, Using ERTS-1 Imagery. Proc. Symp. on Signif. Results Obtained from ERTS-1, Vol. 1, New Carrollton, Md. (1973).

19. Lind, Aulis, O.; Henson, E. Bennette,; \& Pelton, James. Environmental Study of ERTS-1 Imagery: Lake Champlain and Vermont. Proc. Symp. on Signif. Results Obtained from ERTS-1, Vol. 1, New Carrollton, Md. (1973).

20. Polcyn, Fabian C. \& Lyzenga, David R. Calculations of Water Depth From ERTS MSS Data. Proc. Symp. on Signif. Results Obtained from ERTS-1, Vol. 1, New Carrollton, Md. (1973).

21. Yarger, Harold L.; McCauley, James, R.; James, Gerard W.; \& Magnuson, Larry M. Water Turbidity Detection Using ERTS-1 Imagery. Proc. Symp. on Signif. Results Obtained from ERTS-1, Vol. 1, New Carrollton, Md. (1973).

22. Hallberg, George R.; Hoyer, Bernard E.; \& Rango, A. Application of ERTS-1 Imagery to Flood Inundation Mapping. Proc. Symp. on Signif. Results Obtained from ERTS-1, Vol. 1, New Carrollton, Md. (1973).

23. Morrison, Roger B. Assessment of Flood Damage in Arizona by Means of ERTS-1 Imagery. Proc. Symp. on Signif. Results Obtained from ERTS-1, Vol. 1, New Carrollton, Md. (1973). 
24. Paulson, Richard W. Preliminary Analysis of ERTS-Relayed Water Resources Data in the Delaware River Basin. Proc. Symp. on Signif. Results Obtained from ERTS-1, Vol. 1, New Carrollton, Md. (1973).

25. Higer, A. L.; Cordes, E. A.; \& Coker, A. E. Modeling Subtropical Water Level Dynamics Distribution. Proc. Symp. on Signif. Results Obtained from ERTS-1, Vol. 1, New Carrollton, Md. (1973). 


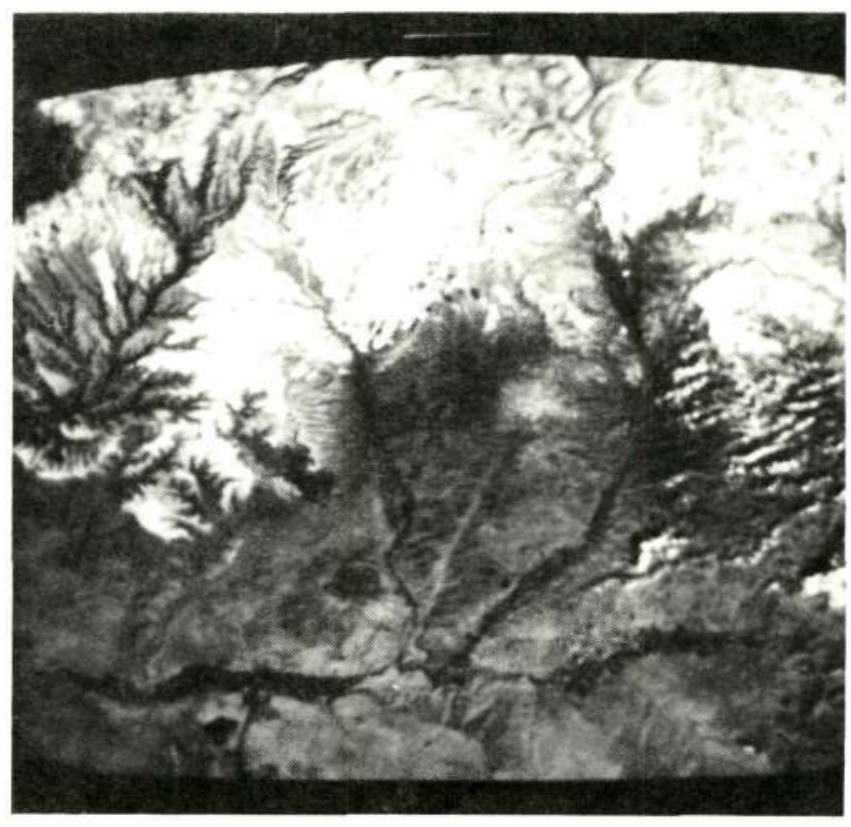

Figure 1. A portion of an ERTS-1 scene taken over

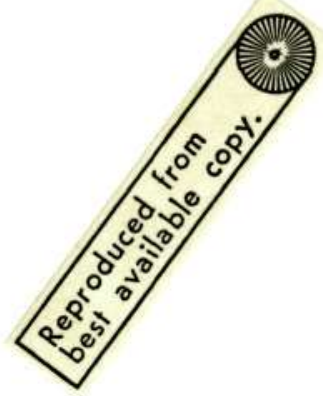
Southwestern Colorado showing the Mancos River drainage basin (upper left) and portions of the La Plata, Animas, and San Juan drainage basins.

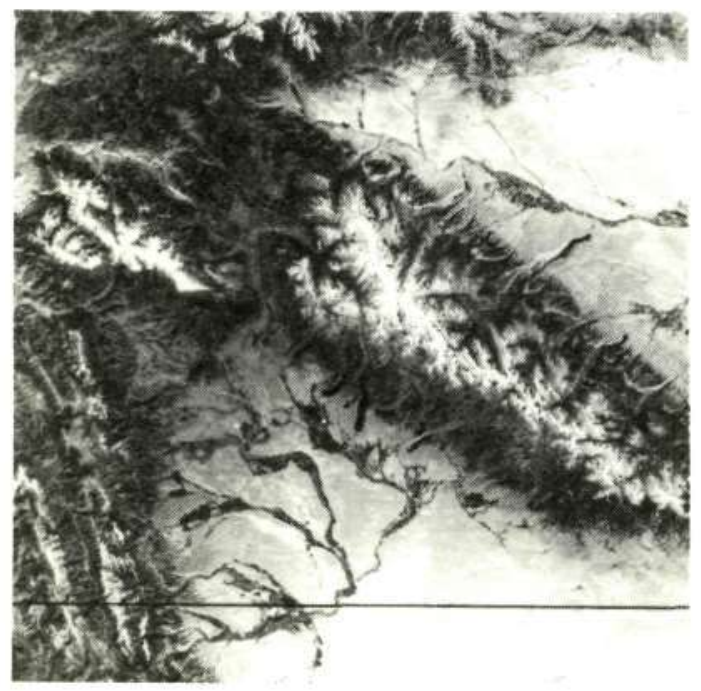

6 Aug. 1972

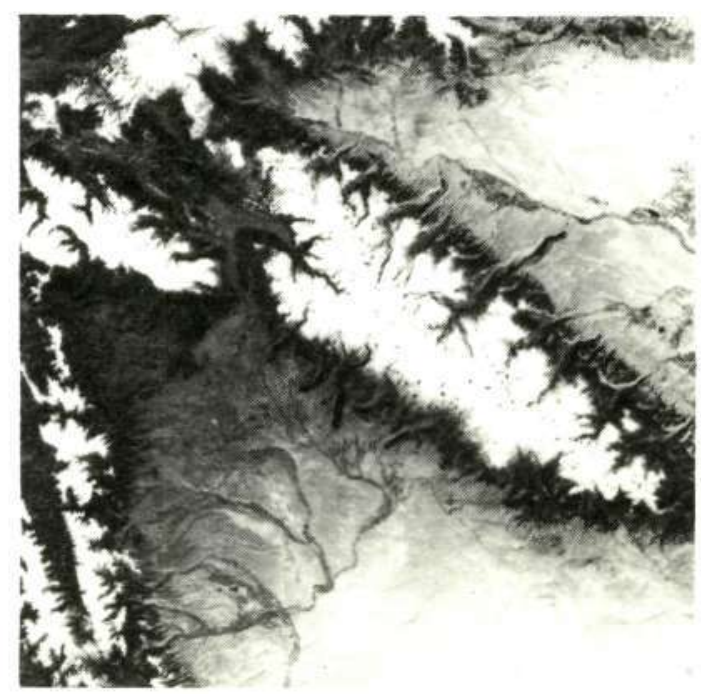

29 Sept. 1972

Figure 2. ERTS-1 snowcover observations in the $0.6-0.7 \mu \mathrm{m}$ spectral region, taken over the Wind River Mountains in Wyoming. Each frame is approximately $186 \mathrm{~km}$ on a side 


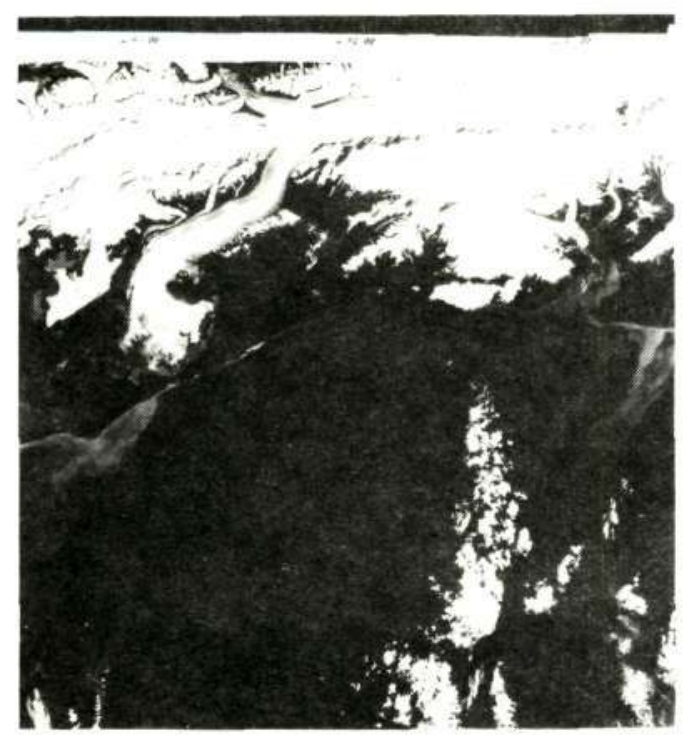

0.5-0.6 $\mu \mathrm{m}$

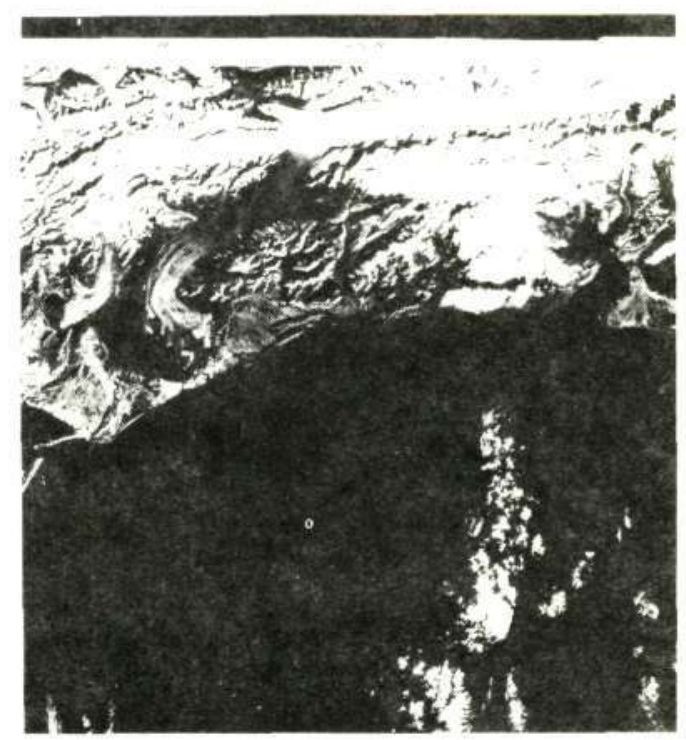

$0.8-1.1 \mu \mathrm{m}$

Figure 3. ERTS-1 observations in two spectral bands over the Bering Glacier on 22 September 1972 in South Central Alaska. The sediment plumes are occurring in the Gulf of Alaska. The frame covers an area $186 \mathrm{~km}$ on a side.

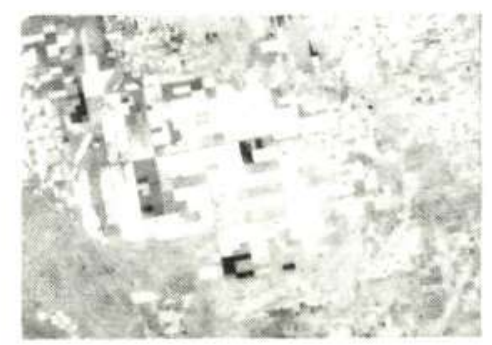

11 August 1972

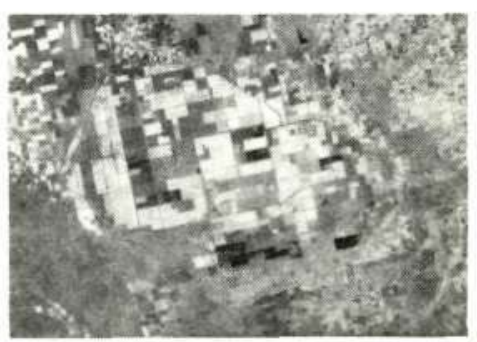

29 August 1972

Figure 4. Portions of two 0.8-1.1 $\mu \mathrm{m}$ observations from ERTS-1 over large irrigation fields in the Tulare Lake Bed area between Fresno and Bakersfield, California. 

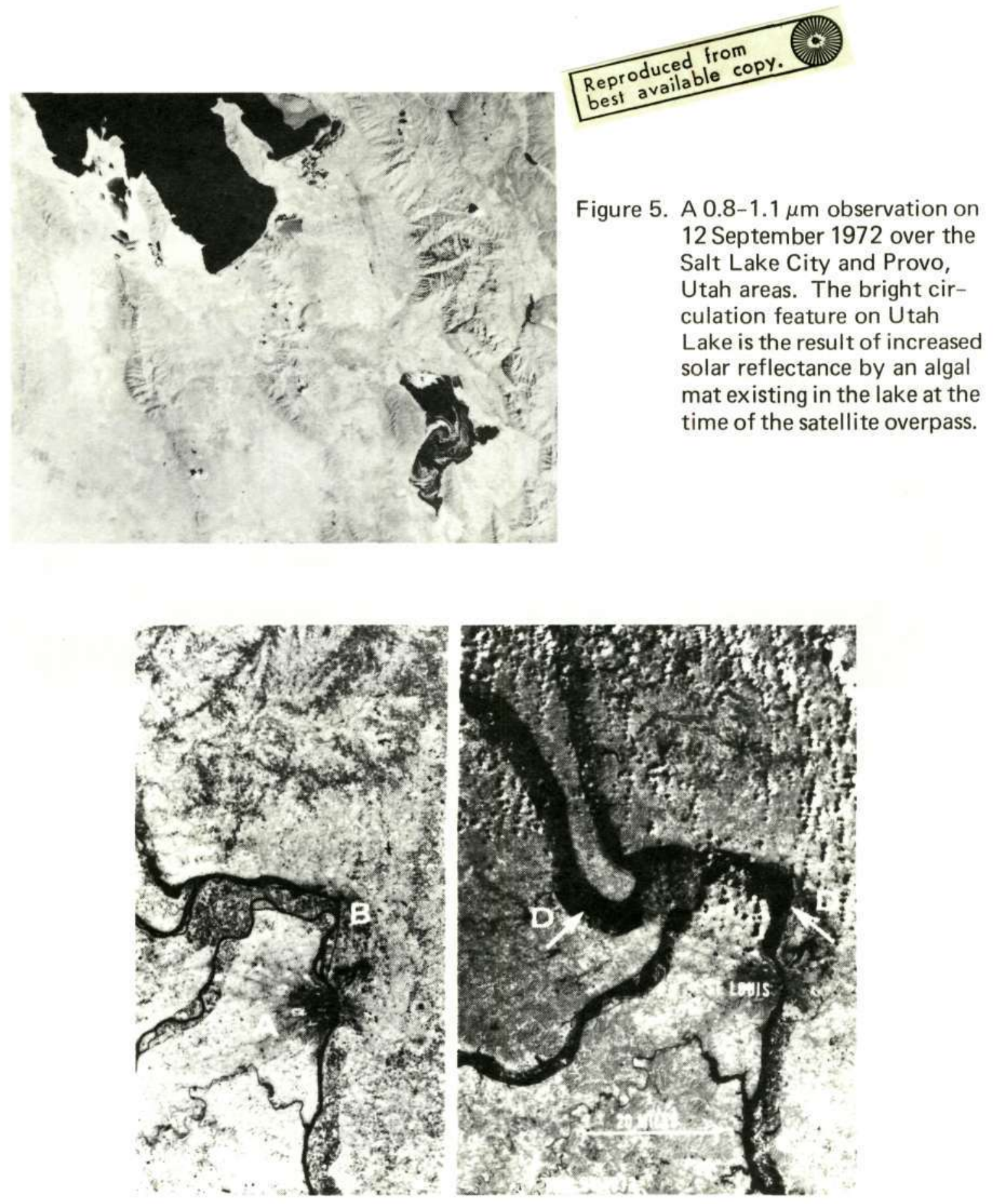

Figure 6. Two views in the 0.8-1.1 $\mu \mathrm{m}$ spectral region from ERTS-1 showing imagery taken before and during the 1973 flooding in the areas near, the confluence of the Illinois River (C) and Missouri River (B) with the Mississippi River near St. Louis (A). The flooded areas appear in the darkest tones such as those areas marked (D). At the time of the March 31 image the river stage at St. Louis was 38 feet and still rising. 